\title{
ON GOD, SUFFERING, AND THEODICAL INDIVIDUALISM
}

\author{
JEROME GELLMAN \\ Ben Gurion University of the Negev
}

Recently, Stephen Maitzen has provided an argument for the nonexistence of God based on ordinary morality. Here is Maitzen's argument, abbreviated down to the relevant parts for my reply and slightly reformulated for ease of presentation:

(1) Necessarily, God permits undeserved, involuntary, human suffering only if such suffering ultimately produces a net benefit for the sufferer. (Maitzen calls this "TI")

(2) If God exists, then necessarily, all undeserved, involuntary human suffering ultimately produces a net benefit for the sufferer. (From 1)

(3) If, necessarily, all undeserved, involuntary human suffering ultimately produces a net benefit for the sufferer, then we never have a moral obligation to prevent undeserved, involuntary human suffering.

(4) We sometimes have a moral obligation to prevent undeserved, involuntary human suffering.

(5) So, it isn't the case that, necessarily, all undeserved, involuntary human suffering ultimately produces a net benefit for the sufferer. (From 3 and 4 )

(6) So: God does not exist. (From 2 and 5)

I will assume the truth of (1), and thus of (2) which follows from (1). My problem is with (3). Maitzen must do much more to show that (3) is true, or even very plausible. My argument is that (a) the set of propositions I am about to list is not implausible, granting God's existence and perfect goodness and a proper understanding of ordinary morality, and 
(b) since that is so, the consequent of (3) does not plausibly follow from (3)'s antecedent.

Let $\mathrm{P}$ be any person that I allow to endure suffering, instead of preventing the suffering. And let $S$ be the particular instance of suffering that $\mathrm{P}$ undergoes. And consider the following set of five propositions, the first four of which are about God and the fifth a moral principle:

(G1) God has so created the world that God is able to produce for P a degree, $\mathrm{D}$, of good for $\mathrm{P}$ that will make P's existence worthwhile.

(G2) God will bring about D for P. This will not be in the form of compensation but a result produced by P's history.

(G3) D is a maximal degree of good that God can produce for P.

(G4) God will bring about D for P whether P suffers (this particular) $\mathrm{S}$ or not. If $\mathrm{P}$ suffers $\mathrm{S}$, then God will produce a net good from $\mathrm{S}$ for $\mathrm{P}$, to offset the evil of $\mathrm{S}$ in order to reach $\mathrm{D}$.

(G5) One can morally allow P to suffer S, if and only if the net benefit to P from allowing $S$ will far outweigh $S$, and either: (a) the net benefit to $\mathrm{P}$ from allowing $\mathrm{S}$ will be far greater than the good that will be P's if one prevents S, or (b) the net benefit to P from one's allowing $S$ will not be less than the good that will be P's if one prevents $S$, and allowing $S$ will significantly increase the net good in the world.

I now explain each of the members of (G1)-(G5):

(G1) and (G2) are consequences of theodical individualism, according to which God must see to it that each person's life be worthwhile, and not just that the existence of the world at large be worthwhile. I include in P's existence P's life after death. I envision the degree of good that is P's in the afterlife as produced by earlier events and not as compensation. I also do not disallow a view like John Hick's wherein we continue to grow and change in the afterlife with new degrees of goodness accruing to our existence.

(G3) follows from God's supreme goodness. There will be constraints upon what the maximal degree of goodness is that God can produce for P. For example, God will want the best distribution of good overall in the world and will want a world that is good overall. So, given such con- 
straints, God will produce the best possible degree of good for P. P will have no claims against God that God did not produce a higher degree of good for her, because her existence is the best it could be without fulfilling her selfish desires to get more for herself on other peoples' accounts.

(G4) reflects the fact that God is so damned smart that God has been able to create the world so that whether $\mathrm{P}$ suffers $\mathrm{S}$ or not, $\mathrm{P}$ will receive D. And it reflects God's goodness, in that God would not allow $S$ to occur if it were to detract from the ultimate net result, D, for P.

(G5) makes a claim about our ordinary morality. It says that while consequentialist reckoning is relevant to the allowing of undeserved, involuntary, human suffering, the morality of allowing such suffering is not purely consequentialist. That is because we have a moral deontological obligation to prevent undeserved, involuntary, human suffering (when able, when appropriately situated, etc.). And while that obligation is defeasible, it is not overridden by a mere net benefit for the sufferer.

What is needed to defeat the deontological obligation not to allow suffering is that either: (a) the net benefit far outweighs the suffering and far outweighs what good would accrue to the sufferer without that suffering; or (b) the net benefit that far outweighs the suffering is at least the same as what good would accrue to the sufferer without that suffering, and produces a significant net increase of good in the world. These are necessary and sufficient conditions for one being allowed not to prevent undeserved, involuntary, human suffering.

On alternative (a), the benefit justifying one's not preventing the suffering is all P's. On alternative (b), however, the benefit that justifies not preventing the suffering is not P's but others'. This can happen in at least two ways. The first is that one might be able to bring a very high benefit to another person by allowing $\mathrm{P}$ to suffer. And the second is that in adjudicating one's moral obligations to others as well as to $\mathrm{P}$ it turns out that one's obligations to others are stronger than, and so defeat, one's obligation to prevent $\mathrm{P}$ from enduring $\mathrm{S}$.

You might protest that (b) violates Maitzen's Kantian stricture, let's call it "K."

(K) Nobody (including God) can treat human beings merely as a means. 
The violation appears to occur because (G5) permits us (and God) to allow $\mathrm{P}$ to suffer in order to benefit others.

However, (G5) does not violate (K), on Maitzen's interpretation of it, which I accept. For Maitzen, $(\mathrm{K})$ prohibits "sacrificing an innocent person who did not ask for it” (p. 116, my emphasis), and (K) prohibits, "exploiting" a person by visiting upon them undeserved, involuntary, human suffering (p. 117). However, (G5) licenses none of these. Remember, whenever (G5) allows the non-prevention of undeserved, involuntary, human suffering the sufferer is either better off or at least as well off as she would have been without having endured that suffering. The only thing that has happened is that the deontological moral obligation that others have not to allow $\mathrm{P}$ to endure undeserved, involuntary, suffering has been overridden by either a justified benefit to $\mathrm{P}$ or to others. This does not constitute a "sacrifice" or "exploitation" of $\mathrm{P}$ in any way, and should not be forbidden by (K). To put it tersely, (G5) does not excuse any instance in which a person treats $\mathrm{P}$ merely as a means.

It is not implausible to assume that the set (G1)-(G5) is true, granting God's existence and perfect goodness and our understanding of ordinary morality. But, then the antecedent of (3):

(3a) Necessarily, all undeserved, involuntary human suffering ultimately produces a net benefit for the sufferer.

does not plausibly imply (3)'s consequent:

(3c) We never have a moral obligation to prevent undeserved, involuntary human suffering.

That my allowing P's undeserved, involuntary suffering will result in a net benefit for $\mathrm{P}$ is, by (G5), not sufficient reason for me to not have a moral obligation to prevent P's suffering. More is necessary. So, (3) is not plausible. Even if all involuntary human suffering ultimately were to produce a net benefit for the sufferer, there would still be instances in which I had a moral obligation to prevent it. Such would be an instance, for example, where the benefit to the sufferer is only slightly more than preventing the suffering would yield.

Moreover, according to (G1)-(G4), it will never be the case that we may allow an instance of undeserved, involuntary suffering on the grounds 
that it will produce a far greater benefit for the person than would preventing the suffering. And that is because in every instance, according to (G1)-(G4), God will in any case bring about the maximum possible degree of good for the person during his existence - whether he endures that particular suffering or not. So the clause (a) of (G5) will never apply to any of us when faced with the opportunity to prevent suffering. For my money, theodical individualism should entail that we always have an obligation to prevent a case of suffering in $\mathrm{P}$, unless the conditions of (G5) are met. In practice, this means that in the great majority of situations, my theodical individualism will obligate preventing suffering. In any case, since (G1)-(G5) is not implausible, (3) is not yet plausible.

Well, now, you ask, what justifies God allowing undeserved, involuntary suffering? After all, (G5) obligates God no less than it does mere mortals. And since God is a perfect being God will faithfully fulfill the dictate of (G5).

On (G1)-(G4), it follows that the suffering God allows a person to endure is such that God allows it either: (i) so as to produce for that person a degree of good that is maximal for that person and also satisfies the conditions of (G5), or: (ii) because allowing it follows from God's juggling of God's obligations to all human persons. Since God is the creator of all persons and sustains them in life at every moment, all human beings stand before God with an equal claim on God to produce for them a maximal possible ultimate benefit in their existence. All human beings are turned to God with an equal claim to a personal maximal net benefit, everything else being equal. Thus, God's obligations to others besides $\mathrm{P}$ are of vastly greater dimensions than that of any human being to other persons. That is at least one reason why God might be justified in allowing suffering in the world, in vastly many cases, while humans have relatively sparse permission to do so. I have already argued that in light of (G1)-(G5) such thinking does not violate the above Kantian stricture about using people as mere means.

One might be skeptical as to whether the world we live in is one where the God of (G1)-(G4) exists. One might doubt, for example, whether every person receives an ultimate benefit that makes his or her existence worthwhile. Such doubts belong to the problem of evil and must be discussed on their own. They do not relate to the present argument against God's existence from theodical individualism. That argument, I have tried to show, fails to convince. 